\title{
How to prioritize urological surgeries during epidemics: Lessons learned from the Toronto SARS outbreak in 2003
}

Roseanne Ferreira, $\mathrm{MD}^{1}$; Melissa McGrath, BASc${ }^{1,2}$; Yuding Wang, $\mathrm{MD}^{1}$; Alp Sener, MD, $\mathrm{PhD}^{3}$; D. Robert Siemens, $\mathrm{MD}^{4}$; Luis H. Braga, $\mathrm{MD}, \mathrm{PhD}^{1,2}$

${ }^{1}$ Clinical Urology Research Enterprise (CURE) Program, McMaster Children's Hospital, Hamilton, ON, Canada; ${ }^{2}$ Department of Surgery/Urology, McMaster University, Hamilton, ON, Canada; ${ }^{3}$ Department of Urology, Western University, London, ON, Canada; ${ }^{4}$ Department of Urology, Queen's University, Kingston, ON, Canada

Cite as: Can Urol Assoc J 2020 March 30; Epub ahead of print. http://dx.doi.org/10.5489/cuaj.6551

Published online March 30, 2020

$* * *$

The current outbreak of COVID-19 was first described as a pneumonia of unknown origin which rapidly spread from the city of Wuhan to main land China and ultimately, throughout the world $[1,2]$. On March $11^{\text {th }}$ the World Health Organization declared the COVID-19 a pandemic and urged countries to refine their planning, monitoring and readiness to act on their confirmed and suspected cases of the virus [3]. While Canada is still considered a low risk country, with currently 3555 patients confirmed with the disease [4], protocols are being rapidly established due to the fluidity of the situation in order to flatten the curve and contain the virus spread rate, which has already succeeded that of the SARS outbreak in $2003[5,6]$.

In the spring of 2003, Toronto experienced the largest SARS outbreak outside Asia with 257 cases and 43 deaths [5-8]. Under the emergency management act, all non-urgent hospital admissions were restricted, unfortunately compliance to this measure was not reinforced in an orderly fashion, based on priorities [7]. During that restriction period, the rate of elective surgery had a modest decreased of $15-22 \%$ during the early and late phases of the outbreak and rates of admissions for urgent surgery remained stable [5,7]. Based on the 2005 Toronto's influenza pandemic prediction model, this reduction in admission numbers represented an insufficient decrease unable to manage the surge capacity when compared to the forecasted rate of admissions [7]. This alerted the need for more efficacious public health policies on restriction of non-urgent clinical activities to increase flow capacity $[8,9]$. At the time of writing of this editorial, most hospitals across Canada have already significantly restricted scheduled (non-urgent) elective urological surgeries. Multiple lists of both cancer and non-cancer cases that should be initially cancelled have circulated on social media. For the benefit of practices across Canada we provide an example protocol to aid in eventual rescheduling in the face of the projected increase to our waiting lists.

The optimal management of elective surgery waiting lists is a multifaceted problem that occurs in different countries regardless of the presence of a universal health care system [10]. To cope with this situation, we suggest this grading system based on risk priority to reschedule elective surgeries and 
manage standby periods (figure 1). Grading occurs from 1 to 4 where "priority 1" is the cluster of the most severe cases based on clinical presentation, presence of red flags and demographics. It is important to point out that classifying patients to a specific priority level is a dynamic and ongoing process where reclassification may be needed based on disease progression as well as, the surgeons clinical judgment. Furthermore, different practices and hospitals with specific foci of urological care may find these suggestions imperfect for their particular situation and regional role; however, we hope this protocol could serve as a starting point for justifying priority of case selection in the coming weeks to months.

Cancelling elective surgery is a crucial step in creating surge capacity to prioritize hospital resources during pandemics. Utilizing priority-based grading strategies to reschedule elective surgery and procedures is a crucial strategy to help mitigate the impact of the COVID 19 outbreak on hospital performance. 


\section{References}

1. Huang C, Wang Y, Li X, et al. Clinical features of patients infected with 2019 novel coronavirus in Wuhan, China. Lancet 2020;395:497-506. https://doi.org/10.1016/S01406736(20)30183-5

2. Li Q, Guan X, Wu P, et al. Early transmission dynamics in Wuhan, China, of novel coronavirus-infected pneumonia. $N$ Engl J Med 2020;382:1199-1207. https://doi.org/10.1056/NEJMoa2001316

3. World Health Organization. Coronavirus disease (COVID-2019) situation reports. Available at: https://www.who.int/docs/default-source/coronaviruse/situation-reports/20200313-sitrep-53covid-19.pdf?sfvrsn=adb3f72_2. Accessed March 2020.

4. Government of Canada. Coronavirus disease (COVID-19): Outbreak update. Available at: https://www.canada.ca/en/public-health/services/diseases/2019-novel-coronavirusinfection.html\#a5. Accessed March 2020.

5. Schull MJ, Stukel TA, Vermeulen MJ, et al. Effect of widespread restrictions on the use of hospital services during an outbreak of severe acute respiratory syndrome. CMAJ 2007;176:1827-32. https://doi.org/10.1503/cmaj.061174

6. Stukel TA, Schull MJ, Guttmann A, et al. Health impact of hospital restrictions on seriously ill hospitalized patients: Lessons from the Toronto SARS outbreak. Med Care 2008;46:991-7. https://doi.org/10.1097/MLR.0b013e3181792525

7. Schull MJ, Stukel TA, Vermeulen MJ, et al. Surge capacity associated with restrictions on nonurgent hospital utilization and expected admissions during an influenza pandemic: Lessons from the Toronto severe acute respiratory syndrome outbreak. Acad Emerg Med 2006;13:122831. https://doi.org/10.1197/j.aem.2006.04.011

8. Hawryluck L, Lapinsky SE, Stewart TE. Clinical review: SARS - lessons in disaster management. Crit Care 2005;9:384-9. https://doi.org/10.1186/cc3041

9. Chu D, Chen RC, Ku CY, et al. The impact of SARS on hospital performance. BMC Health Serv Res 2008;8:228. https://doi.org/10.1186/1472-6963-8-228

10. Kawakami J, Hopman WM, Smith-Tryon R, et al. Measurement of surgical wait times in a universal healthcare system. Can Urol Assoc J 2008;2:597-603. https://doi.org/10.5489/cuaj.974 


\section{Figures and Tables}

Fig. 1. Decision-making algorithm for rescheduling urology elective surgeries post-COVID-19 outbreak.

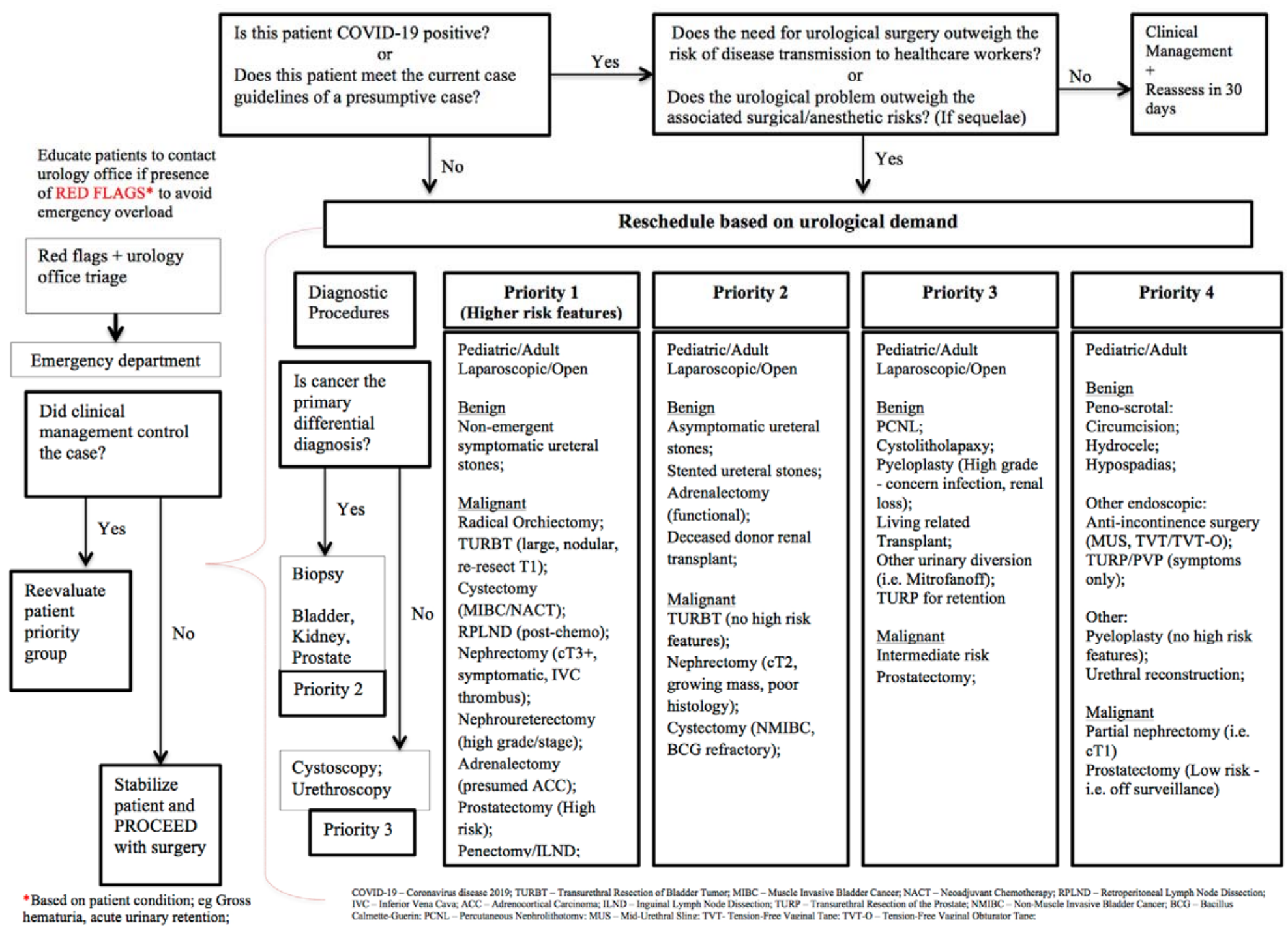

